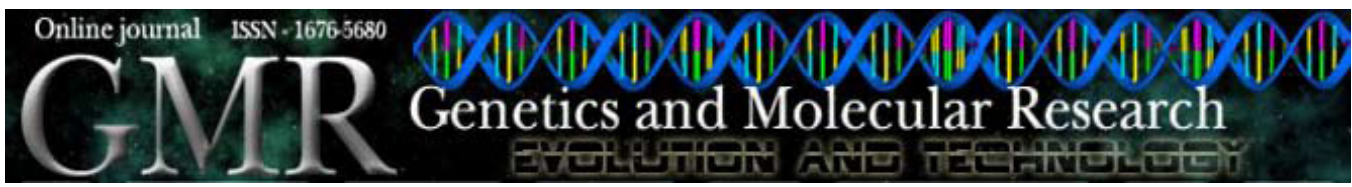

\title{
Simple sequence repeat-based assessment of genetic relationships among Prunus rootstocks
}

\author{
Z. Turkoglu ${ }^{1}$, S. Bilgener ${ }^{1}$, S. Ercisli ${ }^{2}$, M. Bakir ${ }^{3}$, A. Koc ${ }^{4}$, \\ M. Akbulut ${ }^{5}$, R. Gercekcioglu ${ }^{6}$, M. Gunes ${ }^{6}$ and A. Esitken ${ }^{2}$ \\ ${ }^{1}$ Department of Horticulture, Faculty of Agriculture, \\ Ondokuz Mayis University, Samsun, Turkey \\ ${ }^{2}$ Department of Horticulture, Faculty of Agriculture, \\ Ataturk University, Erzurum, Turkey \\ ${ }^{3}$ Ankara University Biotechnology Institute, Ankara, Turkey \\ ${ }^{4}$ Black Sea Agricultural Research Institute, Gelemen-Samsun, Turkey \\ ${ }^{5}$ Pazar Vocational School Rize, Turkey \\ ${ }^{6}$ Department of Horticulture, Faculty of Agriculture, \\ Gaziosmanpasa University, Tokat, Turkey \\ Corresponding author: S. Ercisli \\ E-mail: sercisli@hotmail.com
}

Genet. Mol. Res. 9 (4): 2156-2165 (2010)

Received June 24, 2010

Accepted September 2, 2010

Published November 3, 2010

DOI 10.4238/vol9-4gmr957

\begin{abstract}
Ten SSR loci, previously developed for Prunus, were analyzed to examine genetic relationships among 23 rootstock candidates for sweet and sour cherries, of the species $P$. avium, $P$. cerasus, $P$. mahaleb, and $P$. angustifolia. Five genotypes of $P$. laurocerasus, not used as rootstock, were included in the molecular analysis. The number of alleles per locus ranged from 8 to 12 , with a mean of 9 , while the number of microsatellite genotypes varied from 8 to 17 , indicating that the SSRs were highly informative. The degree of heterozygosity (0.61) was high. Clustering analysis resulted in two main clusters. The first cluster was divided into two subclusters; the first subcluster consisted of $P$. avium and $P$. cerasus, and the second subcluster consisted of $P$. laurocerasus. The second cluster was divided into two subclusters. The first subcluster consisted of $P$. mahaleb genotypes and the second consisted of $P$. angustifolia genotypes. The reference rootstocks also clustered with their associated botanical species. Unweighted pair-group method with arithmetic mean analysis demonstrated that $P$. laurocerasus
\end{abstract}


genotypes had less genetic variation and that $P$. avium genotypes were more closely related to $P$. cerasus. The SSR-based phylogeny was generally consistent with Prunus taxonomy information, suggesting the applicability of SSR analysis for genotyping and phylogenetic studies in the genus Prunus.

Key words: Prunus; SSR; Genotyping; Diversity; Rootstock

\section{INTRODUCTION}

Prunus is a large genus of trees and shrubs, which includes plums, cherries, peaches, apricots, and almonds. The Prunoideae are traditionally classified as a subfamily within the family Rosaceae (Rehder, 1940). Botanical classification of species within this genus is sometimes controversial, partly because of the ease of interspecific hybridization (Dosba et al., 1994). There are many different types of rootstocks being used for Prunus species on a worldwide basis (Rom, 1982). Each one has a particular set of advantages and limitations for adaptation to different geographic regions.

The genomic studies concerning the fruit species have increased enormously in parallel with a renewed interest in fruit germplasm resources and analysis of their genetic diversity including Prunus genus (Aranzana et al., 2003; Romero et al., 2003; Ilgin et al., 2009; Yilmaz et al., 2009; Wünsch, 2009). For crop improvement studies, researchers generally desire abundant genetic diversity among materials.

For breeding and commercialization of promising rootstock candidates, a precise determination and discrimination of these materials is desired. In the case of rootstocks, it is very difficult to observe their morphological traits after grafting. In addition, morphological characters are strongly affected by the environment and also developmental stage of plants (Casas et al., 1999). Therefore, markers independent of the environment are necessary for reliable identification and discrimination of genotypes. The superiority of molecular markers over morphological characterization in fruit species is well established and widely accepted (Ercisli et al., 2007; Zamani et al., 2007; Duminil and Di Michele, 2009).

Microsatellites have been extensively used in Prunus genetics investigations in the last decade (Wünsch and Hormaza, 2004; Lacis et al., 2009; Cheng and Huang, 2009), and the number of microsatellite loci available particularly for Prunus genus has greatly increased. Microsatellite markers, being abundant, multiallelic, and highly polymorphic, provide an efficient and accurate means of detecting genetic polymorphism among fruit species. Most importantly, their codominant nature makes them the markers of choice for population genetic analysis to assess genetic organization in germplasm collections. In Prunus, microsatellites have been used for germplasm characterization (Lacis et al., 2009), determination of genetic diversity (Wünsch, 2009), germplasm management (Cheng and Huang, 2009), parentage analysis (Yamamato et al., 2003), cultivar identification (Xuan et al., 2009), and mapping genetic linkage (Lalli et al., 2008). In Prunus, microsatellites developed in one species have been used in different species, demonstrating their transferability and ability to detect polymorphism (Wünsch, 2009).

Turkey is an important center for Prunus germplasm and diversity. Wild subgenus Cerasus forms exhibit all grades of color, shape, taste and, to a certain degree, size. They are found mainly in mixed forests (up to $2000 \mathrm{~m}$ ), particularly in the Black Sea and Northeast regions of Turkey. These wild germplasms in Turkey have potential in genetic improvement of cherry, primarily as rootstocks (Ercisli, 2004). 
The objective of this study was to identify a set of microsatellite loci that are polymorphic in different rootstock candidates of Prunus species. It is expected that the information presented here will be useful for selection and more efficient utilization of this germplasm in Prunus rootstock breeding programs in the future.

\section{MATERIAL AND METHODS}

\section{Plant material}

Leaf samples of 20 rootstock candidate genotypes belonging to four Prunus species (P. avium, P. mahaleb, P. cerasus, and P. angustifolia), which include selections among wild populations as rootstock candidates in Turkey, were used as starting material to carry out a microsatellite marker analysis. Five P. laurocerasus genotypes were also included in the analysis just to examine genetic relationships with the other Prunus species (Table 1). The genotypes used in this study were obtained from the germplasm collection maintained at the Black Sea Agricultural Research Center in Samsun, Turkey. Three standard Prunus rootstocks, SL64, F12/1 and Montmorency, were also included in analysis.

\begin{tabular}{|c|c|c|c|c|}
\hline Subgenus & Section & Species & English name & Genotypes \\
\hline cerasus & eucerasus & P. avium $\mathrm{L}$. & Sweet cherry & $08 K 53,28 K 20,52 K 42,53 K 08,55 K 92$ \\
\hline cerasus & eucerasus & P. cerasus L. & Sour cherry & $28 \mathrm{VO}, 52 \mathrm{~V} 04,52 \mathrm{~V} 01,55 \mathrm{~V} 22,61 \mathrm{~V} 01$ \\
\hline cerasus & mahaleb & P. mahaleb L. & Mahaleb & $05 M 07,52 M 05,60 M 44,60 M 16,60 M 37$ \\
\hline cerasus & laurocerasus & P. laurocerasus $\mathrm{L}$. & Cherry-laurel & $K 1, K 2, K 3, K 4, K 5$ \\
\hline prunus & prunocerasus & P. angustifolia Marshall & Mountain-cherry & $28 T 01,28 T 02,29 T 02,29 T 03,29 T 04$ \\
\hline
\end{tabular}

\section{DNA extraction}

Genomic DNA was extracted from young leaf tissue using the Wizard ${ }^{\circledR}$ Genomic DNA Purification Kit (Promega, Madison, WI, USA), according to the instructions provided by the manufacturer. Subsequently, an RNAse treatment was performed on the eluted DNA samples. DNA purity and concentration were both checked on $1 \%(\mathrm{w} / \mathrm{v})$ agarose gels and with a NanoDrop ${ }^{\circledR}$ ND-1000 Spectrophotometer.

\section{SSR analysis}

From an initial screening, 10 simple sequence repeats (SSRs) were selected to check for polymorphism by capillary electrophoresis in 28 genotypes of five different Prunus species (Table 1). Polymerase chain reaction (PCR) was conducted using a volume of $10 \mu \mathrm{L}$ containing $15 \mathrm{ng}$ genomic DNA, $5 \mathrm{pmol}$ of each primer, $0.5 \mathrm{mM}$ dNTP, $0.5 \mathrm{U}$ GoTaq DNA polymerase (Promega), $1.5 \mathrm{mM} \mathrm{MgCl}_{2}$ and $2 \mu \mathrm{L} 5 \mathrm{X}$ buffer. The forward primers were labeled with WellRED fluorescent dyes D2 (black), D3 (green) and D4 (blue) (Proligo, Paris, France). Reactions without DNA were included as negative controls. PCR amplification was performed using the Biometra ${ }^{\circledR}$ PCR System. The amplification conditions consisted of an initial denaturation step of $3 \mathrm{~min}$ at $94^{\circ} \mathrm{C}$, followed by 35 cycles of $1 \mathrm{~min}$ at $94^{\circ} \mathrm{C}, 1 \mathrm{~min}$ at $52-56^{\circ} \mathrm{C}$ and $2 \mathrm{~min}$ at $72^{\circ} \mathrm{C}$ with a final extension at $72^{\circ} \mathrm{C}$ for $10 \mathrm{~min}$. The PCR products were first separated on a $3 \%(\mathrm{w} / \mathrm{v})$ agarose gel 
run at $80 \mathrm{~V}$ for $2 \mathrm{~h}$. The gel was then stained with ethidium bromide at a concentration of $10 \mathrm{mg} /$ $\mathrm{mL}$. A DNA ladder (100 bp) (Promega) was used for the approximate size determination of the bands. The amplification products were visualized under UV light, and their sizes were estimated relative to the DNA ladder. For further determination of polymorphisms, the PCR products were run on a CEQTM 8800 XL Capillary Genetic Analysis System (Beckman Coulter, Fullerton, CA, USA). The analyses were repeated at least twice to ensure reproducibility of the results. Allele sizes were determined for each SSR locus using the Beckman CEQTM fragment analysis software. In each run, SL64, F12/1 and Montmorency were included as reference rootstocks.

\section{Genetic analysis}

The genetic "IDENTITY" 1.0 analysis program (Wagner and Sefc, 1999) was used according to Paetkau et al. (1995) for calculating the number of alleles, allele frequency, expected $(\mathrm{He})$ and observed heterozygosity (Ho), estimated frequency of null alleles, and probability of identity (PI) per locus. Genetic dissimilarity was determined by the "MICROSAT" program (version 1.5) (Minch et al., 1995) using proportion of shared alleles, which was calculated by using "ps (option 1 - (ps))", as described by Bowcock et al. (1994). The results were then converted to a similarity matrix, and a dendrogram was constructed with the UPGMA method (Sneath and Sokal, 1973), using the NTSYS-pc software (Numerical Taxonomy and Multiware Analysis System, version 2.0) (Rohlf, 1988).

\section{RESULTS}

An SSR analysis of a total of 28 Prunus genotypes belonging to five different species showed that SSR markers developed for peach, sweet cherry, cherry, plum, and apricot (Table 2) revealed considerable polymorphism. A total of 108 alleles ranging from 8 to 12 per locus with a mean value of 9 alleles per locus were detected based on clarity and specificity (Table 3). Polymorphic bands were obtained with all loci. PS12A02 locus was the most polymorphic

\begin{tabular}{|c|c|c|c|}
\hline SSR primer & Sequence $\left(5^{\prime}-3\right.$ ') & Species origin & Reference \\
\hline Pchgms1 & $\begin{array}{l}\text { GGG TAA ATA TGC CCA TTG TGC AAT C } \\
\text { GGA TCA TTG AAC TAC GTC AAT CCT C }\end{array}$ & Peach & Sosinski et al., 2000 \\
\hline UDP96001 & $\begin{array}{l}\text { AGT TTG ATT TTC TGA TGC ATC C } \\
\text { TGC CAT AAG GAC CGG TAT GT }\end{array}$ & Peach & Cipriani et al., 1999 \\
\hline UDP96005 & $\begin{array}{l}\text { GTA ACG CTC GCT ACC ACA AA } \\
\text { CCT GCA TAT CAC CAC CCA G }\end{array}$ & Peach & Cipriani at al., 1999 \\
\hline UCDCH17 & $\begin{array}{l}\text { TGG ACT TCA CTC ATT TCA GAG A } \\
\text { ACT GCA GAG AAT TTC CAC AAC CA }\end{array}$ & Sweet cherry & Struss et al., 2003 \\
\hline UDAP401 & $\begin{array}{l}\text { AAA CCC TAG CCG CCA TAA CT } \\
\text { GCT AAA GGC CTT CCG ATA CC }\end{array}$ & Apricot & Messina et al., 2004 \\
\hline $\mathrm{UCDCH} 21$ & $\begin{array}{l}\text { TTG TTG ACC ATC GAA TAT GAA G } \\
\text { GAA GGT ACA TGG CGT GCC }\end{array}$ & Sweet cherry & Struss et al., 2003 \\
\hline UDAP404 & $\begin{array}{l}\text { CAT GAA CAG GGT CAA AAG CA } \\
\text { TAT ATC CTT ACG CGG CCT CA }\end{array}$ & Apricot & Messina et al., 2004 \\
\hline CPSCT010 & $\begin{array}{l}\text { TTG GGT AAA TAC TTT ATC ATT TCC } \\
\text { TCC CTG AAT AAG GGT TGT GC }\end{array}$ & Plum & Mnejja et al., 2005 \\
\hline UCDCH31 & $\begin{array}{l}\text { TCC GCT TCT CTG TGA GTG TG } \\
\text { CGA TAG TTT CCT TCC CAG ACC }\end{array}$ & Sweet cherry & Struss et al., 2003 \\
\hline PS12A02 & $\begin{array}{l}\text { GCCACCAATGGTTCTTCC } \\
\text { AGCACCAGATGCACCTGA }\end{array}$ & Cherry & Downey and Iezzoni, 2000 \\
\hline
\end{tabular}




\begin{tabular}{|c|c|c|c|c|c|}
\hline Locus name & No. of alleles & $\mathrm{He}$ & Но & PI & $\mathrm{r}$ \\
\hline PS12A02 & 12 & 0.81 & 0.63 & 0.089 & 0.0943 \\
\hline UCDCH17 & 8 & 0.86 & 0.42 & 0.068 & 0.2380 \\
\hline Pchgms1 & 11 & 0.72 & 0.34 & 0.142 & 0.2193 \\
\hline UDAP401 & 8 & 0.73 & 0.63 & 0.177 & 0.0539 \\
\hline UCDCH31 & 8 & 0.77 & 0.89 & 0.146 & -0.0663 \\
\hline $\mathrm{UCDCH} 21$ & 8 & 0.69 & 0.38 & 0.175 & 0.1860 \\
\hline UDAP404 & 8 & 0.61 & 0.82 & 0.373 & -0.1315 \\
\hline UDP96001 & 11 & 0.81 & 0.54 & 0.084 & 0.1447 \\
\hline UDP96005 & 11 & 0.85 & 0.82 & 0.072 & 0.0175 \\
\hline CPSCT010 & 10 & 0.64 & 0.58 & 0.190 & 0.0404 \\
\hline Total & 108 & 8.64 & 7.31 & & \\
\hline Average & 9 & 0.72 & 0.61 & & \\
\hline
\end{tabular}

$\mathrm{Ho}=$ observed heterozygosity; $\mathrm{He}=$ expected heterozygosity; $\mathrm{PI}=$ probability; $\mathrm{r}=$ null allele frequencies.

among the 10 loci, with the highest effective number of alleles (12 alleles), and was followed by Pchgms1, UDP96001 and UDP96005 (11 alleles) (Table 3).

Observed heterozygosity calculated by direct counts for the putative locus, identified by each primer pair, ranged between 0.34 and 0.89 with a mean value of 0.61 . Among the loci, the Ho values were the highest $(0.89)$ for UCDCH31, while the lowest $(0.34)$ were for the Pchgms1 locus (Table 3). The most informative locus, with regard to the PI, was PS12A02 (12 alleles per locus, PI $=0.089$ ), whereas the least informative locus was UDAP404 ( 8 alleles per locus, PI $=0.373$ ) (Table 3$)$. The 10 selected primer pairs generated distinctive products in the range of 93-272 bp in the five different taxonomic groups (Table 3). The number of microsatellite in the different genotypes ranged from 8 (UDAP401, UCDCH21) to 17 (UCDCH31) with an average of 11.1 and a total of 111 (Table 4).

The genetic similarity measured within and among species ranged $0.95-1.00$ within P. laurocerasus, $0.25-0.50$ within $P$. avium, $0.60-1.00$ within $P$. cerasus, $0.65-0.85$ within $P$. mahaleb, and 0.60-0.80 within $P$. angustifolia genotypes (Table 5). The average similarity ratios within species in descending order were $P$. laurocerasus $(0.97)>P$. cerasus $(0.76)>P$. mahaleb $(0.75)>P$. angustifolia $(0.68)>P$. avium $(0.35)$, respectively. The similarity ratio between standard SL64 and $P$. mahaleb genotypes, F12/1 and $P$. avium genotypes, and Montmorency and $P$. cerasus genotypes ranged from 0.40 to $0.65,0.25$ to 0.40 , and 0.55 to 0.60 , respectively (Table 5).

With respect to similarity between species, the average similarity ratios considering the average of five genotypes of each species was $0.12,0.10,0.05$, and 0.01 between P. laurocerasus and $P$. avium, $P$. cerasus, $P$. mahaleb, and $P$. angustifolia genotypes, respectively. These ratios were $0.34,0.02$ and 0.03 between $P$. avium and the other three species (P. cerasus, $P$. mahaleb and P. angustifolia, respectively). P. cerasus- $P$. mahaleb and P. cerasus-P. angustifolia had 0.04 and 0.06 average similarity ratios, respectively (Table 5).

The genetic diversity detected among the five species studied divided them into two main groups depicted in Figure 1, which are in agreement with their current taxonomic classification and their morphological characteristics. The first cluster was also divided into two subclusters: the first subcluster consisted of $P$. avium and $P$. cerasus, and the second subcluster consisted of $P$. laurocerasus. The second cluster was also divided into two subclusters: the first subcluster consisted of $P$. mahaleb genotypes, and the second consisted of $P$. angustifolia genotypes. The reference rootstocks also clustered with their associated botanical species (Figure 1). 


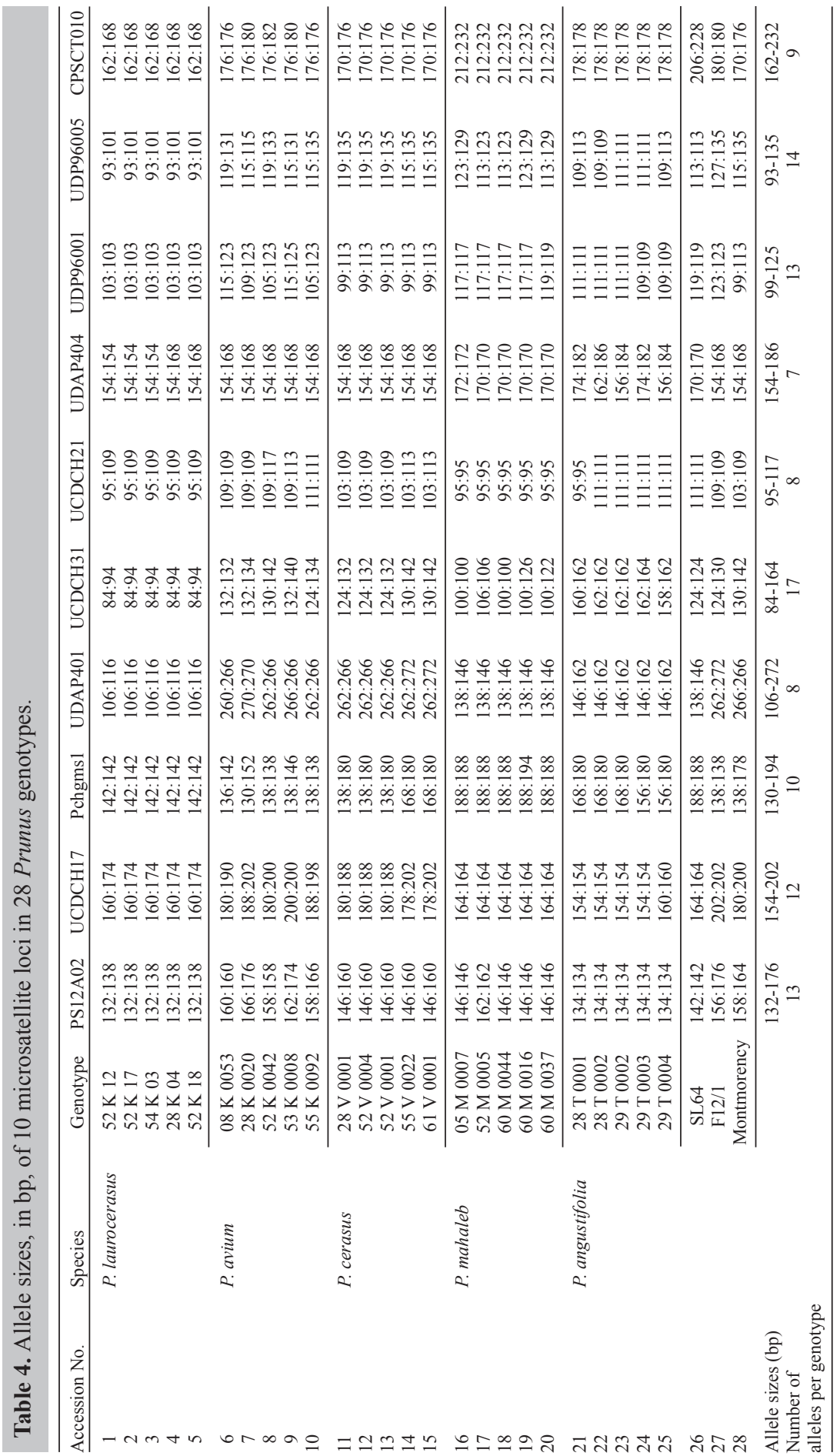




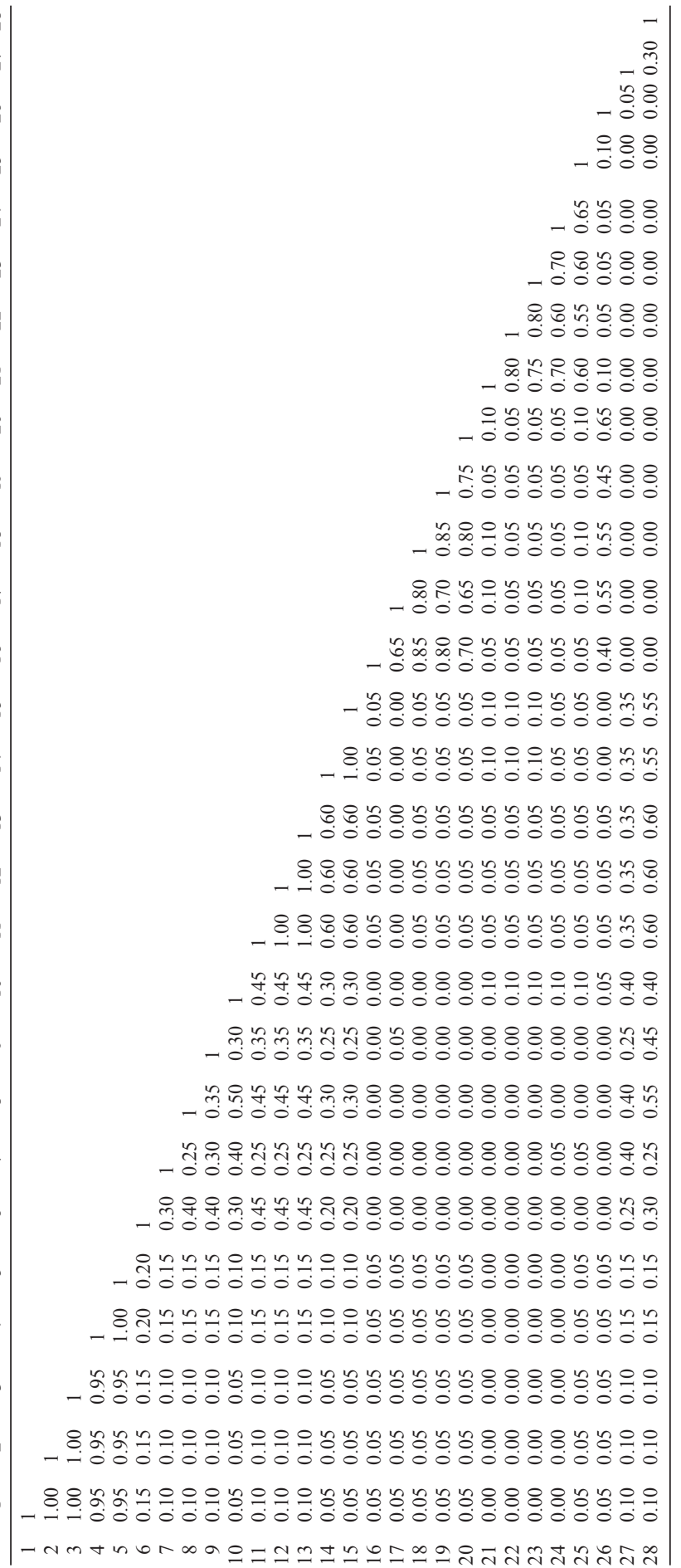




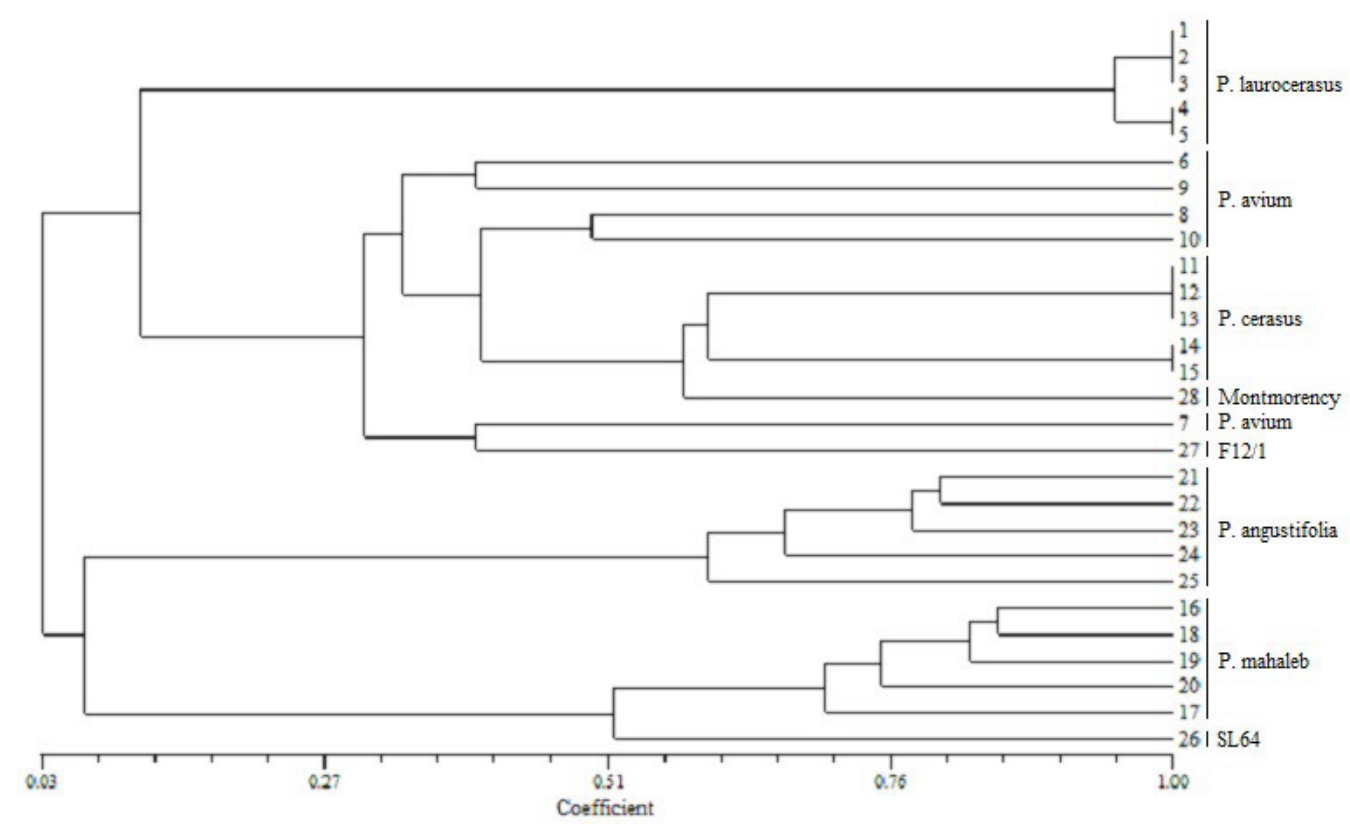

Figure 1. Dendrogram of 28 Prunus genotypes based on UPGMA analysis using the similarity matrix generated by the Nei and Li coefficient after amplification with 10 pairs of microsatellite primers.

\section{DISCUSSION}

In this study, we report for the first time the use of SSR markers for assessing genetic relatedness among 20 promising cherry rootstocks selected from the Black Sea and Northeast regions of Turkey and five P. laurocerasus and three standard rootstocks (SL64, F12/1 and Montmorency). The results obtained in the present study show that microsatellites can be effectively used for fingerprinting purposes in Prunus. In fact, all microsatellite primer pairs tested produced good and various levels of amplifications. As expected, the PS12A02 locus developed for cerasus was the most polymorphic among the six loci with the highest effective number of alleles (12 alleles) and was followed by Pchgms1, UDP96001 and UDP96005 (11 alleles). The results confirm the high transferability of the SSR used among different Prunus species. This transferability across Prunus species was already confirmed by different authors (Dirlewanger et al., 2002; Wünsch and Hormaza, 2002; Bouhadida et al., 2009). Previously, the PS12A02 locus was found to be the most informative in some studies (Downey and Iezzoni, 2000; Wünsch and Hormaza, 2004). The second most informative locus, Pchgms1, was also found to be very informative (11 alleles) in sweet cherries (Wünsch et al., 2004). According to Sefc et al. (2000), the PI value should be over 0.05 , and all loci used in this study had PI values higher than 0.05 , indicating that the selected loci were highly polymorphic for the materials used.

Previously, SSR markers have been widely used for molecular characterizations and similarity relationships among Prunus accessions and have revealed high polymorphism level to discriminate these accessions (Sosinski et al., 2000; Dirlewanger et al., 2002; Wünsch et al., 2004; Maghuly et al., 2005). 
The higher levels of within-group variation observed within P. avium genotypes suggest a complex history of development of $P$. avium along the Black Sea and Northeast Anatolia in Turkey. The introduction and spread of wild and semi-domesticated Prunus species, especially from its native Near East range, domestication of indigenous wild Prunus species, natural hybridization between indigenous and introduced plants, and human selection may have contributed to this high variation.

The highest genetic similarity was detected between $P$. avium and $P$. cerasus with an average similarity value of 0.34 . This was expected as $P$. avium is one of the ancestors of $P$. cerasus.

The observed and expected heterozygosities averaged over the 10 SSR loci were 0.61 and 0.72 , respectively, indicating higher mean values than those reported for SSRs in Prunus species (Aranzana et al., 2003; Bouhadida et al., 2009). High allele number and high heterozygosity obtained in the present study reflect the ability of SSR markers to provide a unique genetic profile for individual plant genotypes.

Such high levels of heterozygosity are commonly observed among clonally propagated, outbred, perennial species, since they are favored during selection and are known to confer greater adaptability, vigor and productivity in clonal varieties (Aradhya et al., 1998; Sefc et al., 2000).

In summary, the gene pool of Prunus surveyed along the Black Sea and Northeast Anatolia in Turkey has significant amounts of genetic variation. In regard to germplasm management, our results show that the germplasm collection is highly variable and that most variation is common to all genetic groups identified. The Prunus germplasm from the region could have economically important adaptive traits that can potentially be incorporated into Prunus breeding programs. Hence, it is expected that the results of this study will assist current Prunus rootstock breeding efforts in Turkey, as well as maintaining the genetic integrity of the genetic resources. These results also demonstrate the high potential of SSR analysis in cherry rootstock identification and studies on diversity in Prunus species.

\section{REFERENCES}

Aradhya MK, Liana Y, Zee FT and Manshardt RM (1998). Genetic variability in Macadamia. Genet. Resour. Crop Evol. 45: 19-32.

Aranzana MJ, Pineda A, Cosson P, Dirlewanger E, et al. (2003). A set of simple-sequence repeat (SSR) markers covering the Prunus genome. Theor. Appl. Genet. 106: 819-825.

Bouhadida M, Casas AM, Gonzalo MJ, Arus P, et al. (2009). Molecular characterization and genetic diversity of Prunus rootstocks. Sci. Hortic. 120: 237-245.

Bowcock AM, Ruiz-Linares A, Tomfohrde J, Minch E, et al. (1994). High resolution of human evolutionary trees with polymorphic microsatellites. Nature 368: 455-457.

Casas AM, Igartua E, Balaguer G and Moreno MA (1999). Genetic diversity of Prunus rootstocks analyzed by RAPD markers. Euphytica 110: 139-149.

Cheng Z and Huang H (2009). SSR fingerprinting Chinese peach cultivars and landraces (Prunus persica) and analysis of their genetic relationships. Sci. Hortic. 120: 188-193.

Cipriani G, Lot G, Huang WG, Marrazzo MT, et al. (1999). AC/GT and AG/CT microsatellite repeats in peach (Prunus persica (L) Batsch): isolation, characterisation and cross-species amplification in Prunus. Theor. App. Genet. 99: 65-72.

Dirlewanger E, Cosson P, Tavaud M, Aranzana J, et al. (2002). Development of microsatellite markers in peach [Prunus persica (L.) Batsch] and their use in genetic diversity analysis in peach and sweet cherry (Prunus avium L.). Theor. Appl. Genet. 105: 127-138.

Dosba F, Bernhard R and Zanetto A (1994). Importance des ressources génétiques des Prunus. C.R. Acad. Agric. Fr. 80: 45-57.

Downey SL and Iezzoni AF (2000). Polymophic DNA markers in black cherry (Prunus serotina) are identified using 
sequences from sweet cherry, peach and sour cherry. J. Am. Soc. Hortic. Sci. 125: 76-80.

Duminil J and Di Michele M (2009). Plant species delimitation: a comparison of morphological and molecular markers. Plant Biosyst. 143: 528-542.

Ercisli S (2004). A short review of the fruit germplasm resources of Turkey. Genet. Resour. Crop Evol. 51: 419-435.

Ercisli S, Agar G, Orhan E, Yildirim N, et al. (2007). Interspecific variability of RAPD and fatty acid composition of some pomegranate cultivars (Punica granatum L.) growing in Southern Anatolia Region in Turkey. Biochem. Syst. Ecol. 35: 764-769.

Ilgin M, Kafkas S and Ercisli S (2009). Molecular characterization of plum cultivars by AFLP markers. Biotechnol. Biotechnol. Eq. 23: 1189-1193.

Lacis G, Rashal I, Ruisa S, Trajkovski V, et al. (2009). Assessment of genetic diversity of Latvian and Swedish sweet cherry (Prunus avium L.) genetic resources collections by using SSR (microsatellite) markers. Sci. Hortic. 121: 451-457.

Lalli DA, Abbott AG, Zhebentyayeva TN, Badenes ML, et al. (2008). A genetic linkage map for an apricot (Prunus armeniaca L.). BC1 population mapping plum pox virus resistance. Tree Genet. Genomes 4: 481-493.

Maghuly F, Fernandez EB, Ruthner S, Pedryc A, et al. (2005). Microsatellite variability in apricots (Prunus armeniaca L.) reflects their geographic origin and breeding history. Tree Genet. Genome 1: 151-165.

Messina R, Lain O, Marrazzo MT, Cipriani G, et al. (2004). New set of microsatellite loci isolated in apricot. Mol. Ecol. Notes 4: 432-434.

Minch E, Ruiz-Linares A, Goldstein DB, Feldman M, et al. (1995). Microsat (Version 1.4d): A Computer Program for Calculating Various Statistics on Microsatellite Allele Data. Stanford University Medical Center, Stanford.

Mnejja M, Garcia-Mas J, Howad W and Arús P (2005). Development and transportability across Prunus species of 42 polymorphic almond microsatellites. Mol. Ecol. Notes 5: 531-535.

Paetkau D, Calvert W, Stirling I and Strobeck C (1995). Microsatellite analysis of population structure in Canadian polar bears. Mol. Ecol. 4: 347-354.

Rehder A (1940). A Manual of Cultivated Trees and Shrubs Hardy in North America Exclusive of the Subtropical and Warmer Temperate Regions. 2nd edn. Macmillan, New York, 162.

Rohlf FJ (1988). NTSYS-PC Numerical Taxonomy and Multivariate Analysis System. Exeter Publishing, New York.

Rom RC (1982). A new philosophy for peach rootstock development. Fruit Variety J. 36: 34-37.

Romero C, Pedryc A, Munoz V, Llacer G, et al. (2003). Genetic diversity of different apricot geographical groups determined by SSR markers. Genome 46: 244-252.

Sefc KM, Lopez MS, Lefort F, Botta R, et al. (2000). Microsatellites variability in grapevine cultivars from different European regions and evaluation of assignment testing to assess the geographic origin of cultivars. Theor. Appl. Genet. 100: 498-505.

Sneath PH and Sokal RR (1973). Numerical Taxonomy. Freeman, San Francisco.

Sosinski B, Gannavarapu M, Hager LD, Beck LE, et al. (2000). Characterisation of microsatellite markers in peach [Prunus persica (L.) Batsch]. Theor. Appl. Genet. 101: 421-428.

Struss D, Ahmad R, Southwick SM and Boritzki M (2003). Analysis of sweet cherry (Prunus avium L.) cultivars using SSR and AFLP marker. J. Am. Soc. Hortic. Sci. 128: 904-909.

Wagner HW and Sefc KM (1999). Identity 1.0. Centre for Applied Genetics. University of Agricultural Science, Vienna. Wünsch A (2009). SSR markers for fingerprinting Prunus species. Acta Hortic. 814: 689-694.

Wünsch A and Hormaza JI (2002). Molecular characterisation of sweet cherry (Prunus avium L.) genotypes using peach [Prunus persica (L.) Batsch] SSR sequences. Heredity 89: 56-63.

Wünsch A and Hormaza JI (2004). Molecular evaluation of genetic diversity and S allele composition of local Spanish sweet cherry (Prunus avium L.) cultivars. Genet. Resour. Crop Evol. 51: 635-641.

Wünsch A, Gella R and Hormaza JI (2004). Molecular characterization of rootstocks for sweet cherry (Prunus avium L.). Acta Hortic. 658: 599-602.

Xuan H, Wang R, Büchele M, Möller O, et al. (2009). Microsatellite markers (SSR) as a tool to assist in identification of sweet (Prunus avium) and sour cherry (Prunus cerasus). Acta Hortic. 839: 507-514.

Yamamoto T, Mochida K, Imai T, Haji T, et al. (2003). Parentage analysis in Japanese peaches using SSR markers. Breed. Sci. 53: 35-40.

Yilmaz KU, Ercisli S, Asma BM, Dogan Y, et al. (2009). Genetic relatedness in Prunus genus revealed by inter-simple sequence repeat markers. HortScience 44: 293-297.

Zamani Z, Sarkhosh A, Fatahi R and Ebadi A (2007). Genetic relationships among pomegranate genotypes studied by fruit characteristics and RAPD markers. J. Hortic. Sci. Biotech. 82: 11-18. 